\title{
Gated Ion Channel
}

National Cancer Institute

\section{Source}

National Cancer Institute. Gated Ion Channel. NCI Thesaurus. Code C16753.

An ion channel in which the ion transport is regulated by a specific stimulus of either a change in membrane potential or binding of a ligand. Once the stimulus occurs the channel may undergo conformational changes that allow selective permeability. 